\title{
Therapeutic effects of building resilience: an observation of two case studies
}

\begin{abstract}
Resilience is an emerging area of research interest. Resilience has much relevance and applicability to persons with disabilities and to the situations lived and experienced by people with disabilities. ${ }^{1-3}$ However, few resilience interventions, specifically tailored to the needs of people with disabilities, have been developed and empirically studied. Stuntzner and Hartley ${ }^{3}$ began to change this trend with the development of a 10-module resilience intervention. Presented as a part of this article are two case studies of people who completed an initial resilience intervention pilot study conducted by Stuntzner and MacDonald. ${ }^{4}$ The case studies represent people living with varying disabilities and diagnoses and illustrate the application and usefulness of resilience interventions in their lives. Based on these initial findings, resilience and resilience-skill building approaches may help assist people with disabilities in reducing negative emotions and cultivating more positive ways of coping. Additional research is warranted to learn more about the utility of resilience interventions among people with disabilities.
\end{abstract}

Keywords: resilience, resilience case studies, interventions, resilience cultivation, rehabilitation
Volume 5 Issue I - 2020

\author{
Susan Stuntzner,' Angela MacDonald, ${ }^{2}$ \\ Michael Hartley ${ }^{3}$ \\ 'Director of Accessible Education, Part-time Lecturer, \\ Southwestern Oregon Community College,University of Texas \\ Rio Grande Valley, USA \\ ${ }^{2}$ Adjunct Faculty, Rehabilitation Counseling and Human Services, \\ University of Idaho, USA \\ ${ }^{3}$ Associate Professor, Disability and Psychoeducational Studies, \\ University of Arizona, USA
}

\begin{abstract}
Correspondence: Susan Stuntzner, Director of Accessible Education, Part-time Lecturer, Southwestern Oregon Community College, University of Texas Rio Grande Valley, USA, Email susan.stuntzne@utrgv.edu
\end{abstract}

Received: December 19, 2019 | Published: January 24, 2020

\section{Introduction}

Resilience is an area of increasing interest in recent years. Resilience is often associated with traumatic and challenging life events such as death, bereavement, natural disasters, loss, and personal crisis. ${ }^{5}$ Over the past decade, rehabilitation scholars have stated that resilience is relevant to the needs of people with disabilities; yet, few interventions and approaches exist ${ }^{6,7}$ to assist people who might benefit from such an approach.

Resilience is referred to as the ability to bounce back or overcome a challenging life event. ${ }^{8}$ Neenan and Dryden ${ }^{9}$ expand this definition and state that resilience is a trait that can help people grow and become stronger following a challenging life event. Stuntzner and Dalton (in press) ${ }^{10}$ increase professionals' understanding of resilience and explain that resilience may include the advent or existence of a disability. However, resilience is about more than the disability and how well someone adjusts to it. Resilience is also relevant to the lived experiences and societal injustices often encountered by people with disabilities and the situations they face because of the disability (Stuntzner \& Dalton, in press). ${ }^{10}$ More specifically, disability is a situation often associated with changes or reductions in personal and physical functioning, employment (i.e., unemployment/ underemployment), health care and finances, social and family support, environmental and attitudinal barriers, and access to equitable societal resources. ${ }^{11,12}$ Compounding these changes is the fact that many people experience multiple barriers, including bias, discrimination, low expectations, and negative societal attitudes (Stuntzner \& Dalton, in press). ${ }^{10}$ Further, many people with disabilities are asked, by society, to cope, adapt, and move forward positively, while being the recipient of inadequate support to help them do so. Compounding the situation is the reality that many people experience changes in earning capacity, financial well-being, and access to an adequate quality of life. ${ }^{13}$
Given the multiple changes and obstacles people with disabilities face, it is evident that resilience interventions can be helpful when people encounter such issues. ${ }^{5}$ Resilience and resilience cultivation can assist people with disabilities in several ways. More specifically, resilience helps reduce negative emotions such as anxiety, depression, stress, and vulnerability and improve positive traits such as forgiveness. ${ }^{4,14,15}$ Resilience also improves peoples' attitude and outlook, self-awareness, and coping skills $;{ }^{3}$ promotes meaning and purpose ${ }^{16}$ develops inner strength; ${ }^{17,18}$ and increases tenacity and perseverance. ${ }^{19}$ Considered collectively, resilience cultivation is a means to help people learn more about themselves, their strengths and abilities (i.e., tenacity, inner strength), and their coping skills. Resilience can help people feel and live better (i.e., less anxiety and depression) and identify skills that no longer work.

\section{Overview of intervention}

Stuntzner and Hartley ${ }^{3,6}$ developed a 10-module resilience intervention specifically designed for people with disabilities and experiences associated with living with a disability. The intervention is comprised of 10 resilience-based skills derived from the supporting literature. The ten skills, presented in the intervention, were selected because they are empirically supported to be factors associated with resilience. ${ }^{20-25}$ These skills were chosen due to the dual nature they have in helping people with disabilities positively cope and adapt to a disability. Resilience-based skills incorporated into this intervention are a merger of these two essential concepts.

Stuntzner and Hartley's ${ }^{3}$ resilience intervention exposes people to 10 resilience-based skills. Resilience-based skills are presented in a logical order with the first five skills creating the foundation for the second half of the intervention. The first five modules are considered concrete and essential before delving into sometimes tricky and 
challenging topics (i.e., forgiveness, self-compassion). Modules 1 through 5 teach people about resilience, attitude and outlook on life, locus of control, mental and emotional regulation, and coping/ problem-solving skills, especially as they relate to the experience of living with a disability. The next five modules are more abstract and build off of previous modules. Modules 6 through 10 help people learn about spirituality, forgiveness, self-compassion, compassion for others, growth and personal transcendence, and personal and family support. After the intervention, people have an opportunity to review what they learned and applied to their life; thus, the final module is about reviewing the skills learned and making decisions about ways to further integrate resilience-based skills throughout their lives.

Two case studies are presented to help illustrate the use of Stuntzner and Hartley's resilience intervention among people with disabilities. The case studies were derived from a pilot study conducted by Stuntzner and MacDonald. ${ }^{4}$ In Stuntzner and MacDonald's resilience intervention pilot study, participants were administered pretests to measure current levels of depression, anxiety, forgiveness, and resilience. Following the pretest, people went through the 10-week, 10 module resilience intervention where they learned and refined resilience-based skills, reflected on their current skills and functioning, applied resilience to specific parts of their lives, explored barriers to skill cultivation, and participated in exercises to promote skill application. When participants concluded the intervention, people were given post-test assessments to determine changes in anxiety, depression, forgiveness, and resilience.

The case studies, below, were chosen because they represent a range of conditions and disabilities (i.e., physical, psychological, and emotional). Having an intervention that can be used with various diagnoses and conditions is essential as people vary in their experience of living with a disability and associated experiences and in their ability to cope. ${ }^{26}$

\section{Case Descriptions}

\section{Case description \#I}

Jack is a 53-year old male. Jack reported having a history of various mental health diagnoses, some of which include Manic-Depression, Borderline Personality Disorder, Post-Traumatic Stress Disorder, and Anxiety. Further, Jack communicated that his disabilities impede his ability to be employed and negatively impact his relationships.

Before the study began, Jack described himself as tenacious and determined to not be dominated by anyone or anything. However, he also shared that he is affected by emotions that lead to self-loathing and feeling like a failure. Jack stated that his "inner resilience" is often lacking and that most of the time, he is living in "survival mode" rather than living the life he wants to live. During this time, Jack was asked how he felt about himself and specific situations since he found out about his disability. Specifically, Jack recalled feeling angry, depressed, hopeless, anxious, and feeling as if nothing will make a difference. He said that he is challenged by disability-related life changes, being unable to forgive himself or others, changes in his quality of life, and has difficulty dealing with how others treat him because of the disability.

At the start of the intervention, Jack saw himself and his life as bleak. Preliminary assessment scores indicated he had severe depression, elevated anxiety, was not feeling very resilient (i.e., below the mean), and found it difficult to forgive. When asked to envision and describe a better life, Jack responded that such a thing is unattainable. He saw his life as one filled with few friends and often felt alone. Jack did not feel accepted by society and had several negative societal experiences of living with a disability and being on Social Security. Jack shared that he had difficulty trusting others and had much inner pain, felt hopeless, and viewed himself as a person who could not effect change or have the life he desired. Nevertheless, each week, Jack came back, learned about resilience-based skills, and diligently completed the intervention exercises and applied them to his daily life.

By the time Jack reached Module 3, Locus of Control, a change in personal insight was evident. It was at this time he shared how 'bleak' many of his thoughts were and that he was able to see how he gives much of his power to other people. In short, Jack reached a pivotal point in his thinking; Jack became more attuned to the reality that he had a choice in whether or not he cultivated an internal locus of control rather than give his power away to other people. Furthermore, Jack gained enormous insight when he realized that many of his selfperceptions and perceptions of others were formed by other people and that before now, he never really had a sense of who he was. From this point on, Jack often communicated that this module was potent in creating a shift in his thinking and how he approached life.

In the coming seven weeks, Jack continued to explore how he felt and thought and worked on the presented skills. He explored his coping skills and the function they served. He was honest about how he used them, and he perceived that they helped him. Some of the skills he identified included: meditation, mindfulness, finding a solution, journaling, exercising, spending time in nature, reframing problems, practicing self-care, using a calming self-talk voice, and acquiring information rather than give in to his fears. Also, Jack was exposed to content and activities that encouraged him to consider his spiritual conscious self, forgiveness, and self-compassion. Jack described his spiritual life as complicated but said that the proposed activities helped him examine his beliefs and practices in a way that he was able to work on integrating the information he learned into a new way of living. Further, Jack found a way to re-connect with God, which is something that he initially expressed was hard for him to do.

Following this initial spiritual/forgiveness work, Jack learned about self-compassion. Jack reported that this module had a vast and profound effect on him. As he worked on himself, Jack found that he was able to be more compassionate toward others and kinder to himself - neither of which Jack reported being able to do previously. Near the end of the study, Jack articulated some goals and changes he was willing to make. Having these goals and an intent to help himself create change was a significant shift from the start of the study. By the end of the 10-module intervention, Jack's attitude had improved, He appeared more hopeful and willing to try new things to help himself have a better life; something he thought was not possible at the start.

Concluding the intervention, Jack rated the resilience-based skills he was exposed to in order of usefulness. Jack stated that learning about locus of control and thought regulation was the most helpful, followed by resilience, outlook on life, emotional regulation, coping skills, and self-compassion. Jack further expanded the authors' understanding of how these skills helped him by stating, "these skills were useful in regaining control of his life, finding refuge in himself, and helping him put things into perspective." He also stated that "he feels more stable, and has an increased clarity of mind and decisionmaking skills". ${ }^{4}$

Jack also shared which parts of the intervention he found most 
helpful in building resilience. When queried about this part of his experience, he stated the most valuable was exposure to the selfassessment exercises as a means to build personal awareness. Also, Jack reported that having the opportunity to brainstorm strategies to build resilience skills was of value along with the proposed application exercises (i.e., visualizations, forgiveness activities). Further, Jack stated that he had "a profound inner release with his practice of forgiveness and that he felt much more resilient, trusting of himself, God, and his ability to accept whatever comes his way with calmness and grace". ${ }^{4}$

Strengthening the changes observed and reported by Jack were the improvements made in his overall functioning. Throughout this study, Jack reported less depression (i.e., 14 point decrease, moderate level), improved resilience (i.e., 15 point increase, within range of the mean), and a higher level of forgiveness (i.e., 35 point increase). He continued to live with anxiety, but he experienced reduced state anxiety by the end of the 10 -week intervention.

\section{Case description \#2}

Sonya is a 57 -year old female. Sonya shared that she lives with fibromyalgia. At the start of the study, Sonya expressed several concerns about the ways the disability affects her daily life. More specifically, Sonya said that she often feels anxious and depressed, gets angry about her physical limitations, and is challenged, emotionally, when it comes to her self-esteem. Sonya also reported some physical concerns such as insomnia, muscle aches, and fatigue. Some of her self-reported strengths included being tough, forgiving, kind, helpful, and insightful. She also stated that she feels she recovers from anger reasonably quickly.

Before the start of the study, Sonya was asked to identify how she feels since she found out about the disability. She stated that she sometimes feels angry, frustrated, depressed, hopeless, and anxious. Sonya also reported that she lives with several disability-related changes, including unemployment, alterations in social support, and adverse treatment from others. Sonya also shared that it is hard to forgive herself and sees herself differently following the disability.

Preliminary assessment scores showed Sonya had moderate depression, severe anxiety, and had room to improve her resilience and forgiveness toward an identified person. At the start of Module 1 , Sonya identified goals that shaped much of what she worked on in the coming weeks. The three goals she said were important included learning (1) not to be embarrassed or ashamed by her disability, (2) what is appropriate and acceptable to discuss about her disability with others, and (3) accept her disability and the way her body functions without berating herself. When asked how Sonya knew her goals were achieved, Sonya stated that she would "accept her condition, not be embarrassed by it, be able to communicate with others about the disability and its associated situations, and not feel less than, anxious, depressed, afraid, or talk to herself in negative ways". ${ }^{4}$ Furthermore, Sonya identified four life domains she found difficult; these life domains included family relationships, advocating for herself, personal life, and adjustment to disability. When asked what "better" looks like, she said that she would feel good about herself, not be anxious, be able to accept her condition, and have a better idea of her strengths. ${ }^{4}$

As Sonya proceeded through Modules 2 through 4 (i.e., Attitude and Outlook, Perspectives
On Locus of Control and Mental and Emotional Regulation), themes consistent with the areas mentioned above surfaced. Some of the topics of concern include:

(a) what other people thought of her especially since she is not working and in social situations where she has to turn people down due to the disability;

(b) self-acceptance of the disability and her abilities;

(c) feeling its permissible to have a disability;

(d) being in an uncomfortable or unmanageable situation as it relates to her physical concerns;

(e) her ability to solve challenging situations that arise; and

(f) being able to express her needs with others (i.e., friends, family, acquaintances, medical providers) as it relates to the disability.

Throughout, Sonya worked on her anxiety about what others think and learned to validate herself and to separate that from what others might think. Skills she wanted to implement, include being direct, identify negative self-talk and learn not to take other people's comments personally, and develop a script she could say when in awkward social situations. ${ }^{4}$ Additionally, Sonya stated she wanted to work on forgiveness, self-acceptance, building confidence, not listening to others' negativity, identifying the positives in situations, becoming stronger, trusting that her symptoms are real, and becoming more informed about fibromyalgia. By Module 4, Sonya shared that she is feeling "more settled, less angry, and more forgiving of herself." She also reported that she is seeing and experiencing more positive things in her life than she previously felt. Sonya began to talk about hope.

The personal work Sonya was doing became evident in the latter part of the intervention. Module 5 was on coping skills and identifying those people use and find helpful. At the end of the module, Sonya's plan to work on coping skills focused less on the emotional and mental hurt, and more on strategies and approaches she would do to help take care of herself and improve her coping (i.e., look for the brighter side, practice self-kindness, meditate, journal, remember and implement coping strategies she has used in the past).

Next, Sonya worked on Module 6, Spiritual Beliefs and Practices. In this module, she admitted to being angry and needing to forgive; however, she also stated that it never occurred to her that she needed to forgive. As she worked through this module, Sonya stated that she needed to forgive a reoccurring situation surrounding her disability rather than a person. The reoccurring situation was the fact that she had repeated negative encounters with people and medical professionals when she tells them about the fibromyalgia, depression, and anxiety and how these impact her. Because of these experiences, she withdraws, feels self-doubt and embarrassment, and has become reluctant to share her situation with others, including healthcare providers. Sonya also realized that these prior experiences negatively impacted the way she felt about compassion and understanding of herself.

Further exploration of forgiveness helped Sonya recognize that some forgiveness work could help her forgive and experience compassion and tenderness toward herself. Sonya learned that as she let go of anger and resentment, she had more space to be creative, be there for others, and experience more compassion and understanding. By the end of Module 6, Sonya was able to identify spiritual practices she was going to work on and incorporate (i.e., meditation, visualization exercises, count her blessings). Additionally, Sonya disclosed that 
she enjoyed this module's visualization activity (i.e., Forgiveness as a Means for Growth and Healing) and wanted to learn how to do more of these kinds of practices.

Module 7 focused on compassion and self-compassion. Sonya learned about self-compassion; she explored the practice of compassion and self-compassion within her own life and as they relate to living with a disability. Sonya disclosed that self-compassion is hard when she perceives she has not met her expectations or is judgmental towards herself. However, Sonya also realized that she has options and self-compassion tools (i.e., pray, meditate, practice guided visualizations, spend time in nature, journal, and listen to soothing music) she could access when things are not going well. Sonya discovered she could give her body and mind self-compassion, as it relates to the disabilities rather than judging herself and the situation. An example of this revelation is her statement, "I can listen to what my body and mind are trying to tell me and are giving me permission not to do". ${ }^{4}$

Module 8 was about growth and transcendence following a disability. Sonya was encouraged to consider positive changes within herself and her life that have occurred because of the disability. Sonya stated that she is "more compassionate, caring, forgiving, flexible, patient, open-minded, and has a better attitude." She also shared that her life is going in the right direction. Such self-descriptions were not used as much at the start of the study. Sonya went onto say that "her situation has provided her with many learning opportunities and has made her life more fulfilling than it might have been." It was at this point, in the study, that Sonya communicated with us that "her participation in this study, just might be the experience that helps her turn the corner and the tools provided to her in this study, can be used to help someone experiencing something similar". ${ }^{4}$ These statements suggest that Sonya has more hope and belief in herself and her ability to implement new skills as well as be able to see that she can use her experiences to help others. In sum, she started to see that there is a positive side to living with a disability.

By the end of the intervention, Sonya showed improvement in several areas. Posttest assessments revealed that her depression was minimal, and her anxiety was significantly less, 23 points, compared to the start of the study. Similarly, Sonya showed a positive change in forgiveness (i.e., 78 point increase) and resilience (i.e., 28 point increase, above the mean) since the start. Sonya's change in functioning is representative of the work she put into herself and of her willingness to explore difficult, personal questions and to identify changes she could make within herself.

\section{Discussion}

The case studies presented, above, illustrate two individuals participation in a 10-module resilience intervention specifically designed by Stuntzner and Hartley ${ }^{3}$ for people with disabilities. As a part of the 10-module resilience intervention, Jack and Sonya learned about resilience and personal functioning, attitude and outlook on life, locus of control, emotional and mental regulation, coping skills, spirituality and forgiveness, compassion and self-compassion, growth and transcendence, social and family support. The intervention concluded with the opportunity to review the skills learned and applied, identify how resilience-based skills impacted their life, share their personal stories, and create a plan for continued practice. ${ }^{3}$ Within each module, both individuals learned about the presented skill, completed and discussed module self-assessment exercises, and applied specific resilience-based skills to one life domain chosen in Module 1. They also explored any personal barriers so resilience skill cultivation and were asked to address them. Furthermore, both participated in module exercises to promote skill application.

Jack's story, Case Description \#1, is one of a person living with various mental health diagnoses. Jack's initial assessments are consistent with much of what he discussed and addressed throughout the study. At the start, Jack's assessments revealed he had severe levels of depression, elevated anxiety, and did not see himself as resilient or forgiving. Simultaneously, he shared that he often feels like a failure, is self-loathing, depressed, hopeless, and anxious. Jack also stated he was unable to forgive himself or others and that he lacked inner resilience. His initial comments and descriptions about himself were consistent with what the assessments indicated. Despite Jack's initial feelings and perspectives, he showed up every week and threw himself into the resilience intervention study.

Module 3, Perspectives on Locus of Control, was a pivotal juncture in Jack's self-insight and empowerment. It was during this module that Jack first realized, with a sense of clarity, how negative and selfdefeating many of his thoughts, feelings, and behaviors were. Jack had an enormous epiphany, which he shared with his peers about how he gives his power away to others. As the study continued, Jack often re-referenced how vital this skill was to him in changing the way he viewed himself, his life, and the choices he made.

Module 6, Spiritual Beliefs and Practices, and Module 7, Compassion for Self and Others, represented another pivotal point for Jack. Module 6 incorporated information and exercises about forgiveness and the process of forgiveness. As mentioned previously, Jack declared that forgiveness was hard for him, and indeed, this was an arduous and slow process. Our goal, though, was no to imply that Jack or anyone needed to achieve total forgiveness. Instead, we intended to help people consider forgiveness as a means of healing and to at least ask themselves if they are willing to work on it. As it turned out, Jack was willing to try, but he often let us know that forgiveness was hard and messy. He also shared that it would have been helpful to have more time to work on it. We, the researchers, agreed that forgiveness is hard when real injustice has occurred, and it is a process that occurs over time. Jack's work on forgiveness paved the way for self-compassion. Similar to forgiveness, self-compassion was a skill that Jack reported was immensely helpful and had a profound effect on him.

As the intervention conclusion approached, Jack shared that he would be interested in continuing these skills and in learning more. Jack also communicated that he has sought help in the past, but that he particularly liked the way this intervention was structured. More specifically, Jack found it helpful to work on his thoughts, feelings, and behaviors (i.e., Modules 1 -5) before being asked to work on more abstract topics (i.e., forgiveness, self-compassion) as well as some of the chosen activities.

Much of Jack's self-reported insight and change was captured in the post-test assessments. As previously stated, Jack's assessment scores reflect a reduction in depression and an increase in forgiveness and resilience. Although his anxiety scores did not show change, his behavior, and the way he talked about himself did. By the end of the intervention, Jack gained some self-insight and coping tools he identified as being helpful and would use going forward. Jack had a plan and acted empowered and hopeful; the person we observed Jack become was one who now felt and acted as if the choices he made would make a difference in his life. Many of the changes Jack was 
making are captured in his statement about "having a profound inner release, learning to practice forgiveness, trusting himself and God, feeling more resilient, and believing he could accept situations that come his way". ${ }^{4}$

Sonya's story, Case Description \#2, describes her struggle in accepting the changes brought about in her life because of fibromyalgia. Sonya talked about the physical concerns she had (i.e., muscle aches, fatigue), but she also discussed her challenges in living with fibromyalgia, depression, and anxiety. Some of Sonya's concerns were not being able to accept the disability-related changes in functioning, feeling embarrassed or ashamed about the disability (i.e., self-esteem, self-acceptance), and knowing how to navigate social and interpersonal situations related to her disability. These concerns can be captured under the life domain, adjustment to disability; however, within this life domain were additional topics (i.e., self-advocacy, family beliefs, and relationships surrounding the existence of a disability).

In the coming weeks, Sonya worked through the presented skills and applied them to her life and identified concerns (i.e., adjustment to disability, self-acceptance, self-advocacy). In the first few weeks, similar to Jack, Sonya examined her thoughts and feelings. Sonya worked on changing the way she interpreted others' comments about the disability and its associated limitations throughout her daily life. Similarly, she tried to identify ways to make herself more comfortable in awkward social situations.

During Module 3, Perspectives on Locus of Control, Sonya began to express some emotional relief and comfort. In this module, she worked on identifying specific, stressful life situations. Within each event, Sonya identified self-induced and other induced-barriers, ways these barriers affected her, and positive choices that could be made. Additionally, she worked on understanding her beliefs about herself, her abilities, and the world around her. Sonya was diligent in identifying and processing the ways her beliefs affect her and in examining outcomes when she practices internal locus of control versus external locus of control. After this module, similar to Jack, Sonya seemed to be starting to turn a corner. It was at this point in the intervention that Sonya expressed she felt "less angry, less guilty, more hopeful and forgiving of herself, and was appreciating some of the positive things in her life". ${ }^{4}$

The work Sonya completed in Module 3 was only the beginning. Over the next seven modules, Sonya continued to acquire insight, apply skills to her life, and grow. During this time, Sonya talked less about her emotional hurt and more about the strategies she could try and implement (i.e., look for the brighter side, practice selfkindness, meditate, journal, practice guided meditation, listen to soothing music). Hearing and observing this was positive as this a vital component of the intervention; we, the authors, tried to stress. The message we wanted participants to understand is that resilience is an individually-tailored approach; some skills will resonate while others may not. Furthermore, if one skill or coping strategy does not work, then try another, as a goal of the intervention is to help people sort out and identify skills that help versus those that do not (Stuntzner \& MacDonald, 2014).

Similar to Jack's experience, Modules 6 and 7, seemed to help Sonya moved forward, perhaps in some unexpected ways. Module 6 , Spiritual Beliefs and Practices, incorporated the concept and practice of forgiveness. Throughout, Sonya explored some of her barriers to forgiveness. She stated that she "shuts down" when she is angry and "has never considered the need for forgiveness." As Sonya explored forgiveness, she expressed that she could trust herself and what she feels, and work on not blaming others for how she feels when social interactions go awry. Furthermore, Sonya talked about visualizing and practicing self-care and began to recognize some benefits of forgiveness (i.e., less angry, less concern over what others think, have more personal space for creative endeavors, enhance one's feeling on compassion).

The work completed in Module 6, similar to that reported by some of Sonya's peers, ${ }^{4}$ assisted Sonya in exploring compassion and selfcompassion, which were addressed in Module 7. In this module, Sonya admitted that she has historically not been compassionate towards herself and that this was hard for her. Instead, she reported being stymied by embarrassment and feelings of uselessness and sometimes experiencing self-loathing. ${ }^{4}$ Nevertheless, Sonya continued to explore the skill of self-compassion and was able to identify and implement several self-compassion tools. Of great interest was our observation of Sonya applying compassion and self-compassion to her body, mind, and physical functioning, an approach she reported as not previously doing.

Sonya's case is different from Jack's several ways, one of which is the fact that Sonya lives with a physical disability (i.e., fibromyalgia) in addition to anxiety and depression. While both individuals reported some mental health concerns and/or diagnoses, they differ. Nevertheless, Sonya is another individual who displayed improvement in her mental and emotional functioning throughout the intervention. By the end of the 10-module resilience intervention, Sonya's change scores indicated she had less depression (i.e., minimal) and anxiety (i.e., average) as well as positive change in forgiveness and resilience.

The two people described in these case descriptions are part of a more extensive study conducted by Stuntzner and MacDonald. ${ }^{4}$ Participants in these scholars' study included people living with several reported conditions (i.e., fibromyalgia, kidney failure, PTSD, arthritis, Gout, Borderline Personality Disorder, Manic Depression, anxiety, depression, chronic pain, Narcolepsy, Chron's Disease, Lupus). Preliminary group data, from Stuntzner and MacDonald's ${ }^{4}$ study show that the 10-module resilience intervention helped people significantly reduce depression and anxiety and increase forgiveness and resilience. Similar to Jack and Sonya, participants completed pretests, the 10-module resilience intervention, and posttests. The two cases presented, in this article, illustrate individual experiences of people working through the intervention and describe their experiences and some of the changes they underwent.

Professionals who work with people with disabilities are encouraged to consider resilience and the integration of resilience approaches as a part of their work. An essential feature of the resilience study and cases is the idea that resilience is individually tailored to people's needs and that the skills people find meaningful and of value varies. As a part of Stuntzner and MacDonald's ${ }^{4}$ work and with the presented case studies, people were encouraged to try out the resilience-based skills, apply them to their life, but also determine which skills work for them and those that do not. Furthermore, people were encouraged to reconnect with skills they used to practice but have since stopped and to explore new skills not presented.

Another strength of Sonya and Jack's experience is that people may have different disabilities and areas of their life they want to apply resilience too, but still report improvement. Jack worked on a lot of personal concerns, especially his thoughts and feelings towards himself and on his ability to help himself. Sonya addressed issues that can be captured under adjustment to disability and personal 
relationships. Both cases are representative of what the resilience intervention was designed to do. The intervention was developed so that people could work on building resilience while applying the skills they learn to individually tailored parts of their lives (i.e., personal, family, relationships, self-advocacy, employment, adjustment to disability: Stuntzner \& Hartley, 2014b) $)^{3}$ and still benefit. Since few studies exist that explicitly address resilience and the cultivation of resilience skills among persons with disabilities ${ }^{15}$ to date, there are not many comparable case studies or resilience intervention studies to compare these cases too. Preliminary findings from the more extensive pilot study conducted by Stuntzner and MacDonald ${ }^{4}$ can be used to assist professionals in understanding that resilience interventions are one way to help people with disabilities cultivate resilience and resilience-based skills individually and as a part of a group.

Second, the two presented case studies represent two people's experiences in building resilience and resilience-based skills. Because the sample size is small $(\mathrm{N}=2)$, the information provided may not be generalizable to larger populations. For this reason, further studies warranting the use of this resilience intervention, and others are recommended.

A third limitation is that little is known about the maintenance of change over time. For purposes of this study and these cases, change in depression, anxiety, forgiveness, and resilience was measured from pre-test to post-test. Not included as a part of this article is long-term change (i.e., 2- 3 months following the intervention). Research that examined long-term change is warranted.

\section{Acknowledgements}

None.

\section{Conflicts of interest}

The authors declare no conflicts of interest.

\section{References}

1. Hartley MT. Increasing resilience: Strategies for reducing dropout rates for college students with psychiatric disabilities. American Journal of Psychiatric Rehabilitation. 2010;13:295-315.

2. Hartley MT. Investigating the relationship of resilience to academic persistence in college students with mental health issues. Rehabilitation Counseling Bulletin. 20103;56:240-250.

3. Stuntzner S, Hartley M. Stuntzner and Hartley's life enhancement intervention: Developing resiliency skills following disability. Ahmedabad, Gurat, India. Counseling Association of India. 2014b.

4. Stuntzner S, Mac Donald A. Developing resilience skills following a disability: Anintervention to assist persons with disabilities in learning to adjust to disability and with overall coping. Unpublished data from a research study approved by the University ofIdaho Review Board. 2014.

5. Stuntzner S. Resilience and disability: creation of an online course for professionals. Rehabilitation Counselors and Educators Journal. 2016;9(2):63-72.

6. Stuntzner S, Hartley M. Resiliency, coping, and disability: The development of a resiliency intervention. ACA VISTAs, Spring Issue. 2014a.
7. White B, Driver S, Warren AM. Considering the resilience of people with traumatic disabilities. Rehabilitation Psychology. 53(1):9-17.

8. Edhe DM. Application of positive psychology to rehabilitation psychology. In: RG. Frank, M Rosenthal, editors, 2nd ed. Handbook of rehabilitation psychology. 2009;417-424.

9. Neenan M, Dryden W. Understanding and developing resilience. Journal of Clinical Psychology. 2012;58:307-321.

10. Stuntzner S, Dalton JA. (in press). Behavioral health service delivery among persons with disabilities. In: L Benuto, J Singer, editors, Handbook for cultural factors in behavioral health: A guide for the helping professionals. Springer Publishing. 2018.

11. Hartley MT, Tarvydas VM. Rehabilitation issues, social class, and counseling. In: W Liu, editor. Oxford handbook of social class in counseling psychology. New York, NY: Oxford University Press. 2013:218-228.

12. Marini I, Glover-Graf NM, Millington MJ. Psychosocial aspects of disability: Insider perspectives and counseling strategies. New York, NY: Springer Publishing. 2013.

13. Stuntzner S. Resilience: A pathway to healthier and happier living. Coeur d'Alene Press. 2015.

14. Dwiwardani C, Hill PC, Bollinger RA, et al. Virtues to develop from a secure base: Attachment and resilience as predictors of humility, gratitude, and forgiveness. Journal of Psychology and Theology. 2014;42(1):83-90.

15. White B, Driver S, Warren AM. Resilience and indicators of adjustment during rehabilitation from a spinal cord injury. Rehabilitation Psychology. 2010;55(1):23-32

16. Southwick SM, Charney DS. Resilience: The science of mastering life's greatest challenges. New York, NY: Cambridge University Press. 2012.

17. Moore $\mathrm{C}$. The resilience break-through: 27 tools for turning adversity into action. Austin, TX: Geenleaf Book Group LLC. 2014.

18. Park CL. Kennedy MC. Meaning violation and restoration following trauma: Conceptual overview and clinical implications. In EM Altmaier, editor. Reconstructing meaning after trauma: Theory, research, and practice. San Diego, CA: Elsevier. 2017:17-18.

19. Eisenberg D, Ketchen-Lipson S, Posselt J. Promoting resilience, retention, and mental health. New Directions for Student Services. 2016;156:87-95.

20. Black K, Lobo M. A conceptual review of family resilience factors. Journal of Family Nursing. 2008;14:33-54.

21. Dunn DS, Brody C. Defining the good life; Following acquired physical disability. Rehabilitation Psychology. 2008;53(4):413- 425.

22. Farley YR. Making the connection: Spirituality, trauma, and resilience. Journal of Resilience and Spirituality in Social Work. 2007;26(1):1-15.

23. Miller ED. Reconceptualizing the role of resilience in coping and therapy. Journal of Loss and Trauma. 2003;8:239-246.

24. Walsh F. Strengthening family resilience. New York, NY: Guilford. 1998.

25. Webb JR. Spiritual factors and adjustment in medical rehabilitation. Journal of Applied Rehabilitation Counseling. 2003;34:16- 24.

26. Livneh H. A unified approach to existing models of adaptation to disability. Part I: A model of adaptation. Journal of Applied Rehabilitation Counseling. 1986;17:5-16. 